\title{
HAIR TONIC SHAMPOO FORMULATION WITH AMBON BANANA (MUSA ACUMINATA COLLA) CORM EXTRACT
}

\author{
TETI INDRAWATI ${ }^{*}$, LASTIAR SIMANJUNTAK ${ }^{1}$, DIAH KARTIKA PRATAMI²
}

1Departement of Pharmacy, Faculty of Pharmacy, National Institute of Science and Technology, South Jakarta, DKI Jakarta, 12630, Indonesia, ${ }^{2}$ Lab of Pharmacognosy and Phytochemistry, Faculty of Pharmacy, Pancasila University, Jakarta, 12640, Indonesia Email: teti_indrawati@istn.ac.id

Received: 15 Apr 2020, Revised and Accepted: 06 Jul 2020

\section{ABSTRACT}

Objective: Banana waste, especially corms, has potential as a source of haircare agents due to its active compound, anthraquinone, which is known to promote hair growth. This study aimed to assess preparations of hair tonic shampoo containing Musa acuminata Colla corm extract and evaluate their characteristics and stability.

Methods: Three shampoo formulas were prepared containing $8 \%, 10 \%$, and $12 \%$ corm extract. Physical stability tests were performed at high $\left(60 \pm 2{ }^{\circ} \mathrm{C}\right)$ and room temperature $\left(25 \pm 2{ }^{\circ} \mathrm{C}\right)$ for three weeks. The shampoo formulas were evaluated for their organoleptic properties (colour, form, and odour), homogeneity, $\mathrm{pH}$, density, viscosity, rheology, foam height and stability, and surface tension.

Results: The shampoo formulas with corm extract were white to yellowish-white, creamy, and smelled of banana, and were homogenous without precipitation. The formulas had a pH of $6.08-6.12$, a density of $1.027-1.054 \mathrm{~g} / \mathrm{ml}$, foam height of 3.56-3.63 ml, the surface tension of $28.92-29.85$ dyne/cm, viscosity of 16,000-120,000 cps and pseudoplastic flow properties.

Conclusion: The natural hair tonic shampoo formulas prepared with M. acuminata corm have good characteristics.

Keywords: Hair tonic, Musa acuminata corm, Shampoo, Banana waste

(C) 2020 The Authors. Published by Innovare Academic Sciences Pvt Ltd. This is an open access article under the CC BY license (http://creativecommons.org/licenses/by/4.0/) DOI: http://dx.doi.org/10.22159/ijap.2020v12i5.37918. Journal homepage: https://innovareacademics.in/journals/index.php/ijap

\section{INTRODUCTION}

Banana plants, including their corms, are known to contain chemica compounds such as anthraquinones that promote hair growth [1] Banana is widely cultivated in Indonesia, especially in rural areas They have been traditionally grown in tropical and subtropical regions in rural and urban home gardens and mixed gardens [2] One of the best-known bananas in Indonesia is the Ambon banana (Musa acuminata Colla) [3]. Traditionally, the sap of the banana corm has been used to promote the growth of bushy black hair. The banana plant that has been cut and poured, after 24-48 h the hole will sap in clear liquid removed from the hole [4]. Extracts of the Ambon banana corm contains secondary metabolites, such as anthraquinones, saponins, flavonoids, ascorbic acid, quinones, lectins, and tannins [5, 6]. Extracts of plants containing anthraquinones have been used to prevent hair loss and promote hair growth [7]. The banana corm is usually discarded as waste. However, it can be developed into a useful and profitable source of compounds used in cosmetic preparations, such as shampoos, hair cream baths, and hair tonics [8]

Haircare cosmetics of the future should be safe and effective. Thei effects should be localized, and they should not be harmful to mucous membranes, hair and skin, and should be safe to the body as a whole; in addition, they should be easy to use and be able to be applied topically [8]. All these aspects are mainly determined by the materials used and the way of manufacture, storage, and use of preparations [9]. Currently, many natural shampoo formulations are based on synthetic detergents and other chemical additives, with herbal extracts, added only to increase their efficacy. Amin et al. studied a herbal shampoo made from green tea [10]. Al Badi and Khan studied a natural shampoo derived from five herbal extracts (Acacia concinna, Sapindus mukorossi, Phyllanthus emblica, Ziziphus spina-christi, and Citrus aurantifolia) in different proportions in a $10 \%$ aqueous gelatin solution [9]. A cream bath formulation made with banana corm extracts with a $4 \%$ concentration had the best effect on hair growth [1].

Our study aims to develop a shampoo preparation from the Ambon banana plant as a sustainable way to make use of a waste by-product of its cultivation. We prepared a herbal hair tonic with an extract of M. acuminata corm and evaluated its characteristics and stability.

\section{MATERIALS AND METHODS}

\section{Materials}

Ambon banana corms were obtained from the Indonesian Spice and Medicinal Crops Research Institute (Balitro) Bogor, West Java, Indonesia. The Ambon banana has the taxonomic plant identification no. 1166/IPH.1.02/lf.8/VII/2014 at Herbarium Bogoriense, Botanical Division, Research Center for Biology, Indonesian Institute of Sciences (LIPI) Bogor. Methylparaben, propylparaben, sodium metabisulphite, aqua dest, Sudan III, methylene blue, sodium lauryl ether sulphate, citric acid, cocamidopropyl betaine, and propylene glycol were purchased from Brataco Chemical Co. (Jakarta, Indonesia). Hydroxypropyl methylcellulose (HPMC) was purchased from Sarda Co. (Jakarta, Indonesia).

\section{Preparation of Musa acuminata corm extract}

The Ambon banana corms were washed first, cut into small pieces, and then added to water at a ratio of 1:10 water: banana pieces by volume and blended until smooth. The blended mixture was filtered using filter paper, and sodium metabisulphite added to the filtrate, which was then stored at $4{ }^{\circ} \mathrm{C}$. The extract was used for organoleptic observations, $\mathrm{pH}$ measurement, and phytochemical screening.

\section{Phytochemical screening of corm extract}

Phytochemical screening was performed to analyse anthraquinones, flavonoids, saponins, and tannins, according to the method of Munir et al. with some modifications [11].

\section{Preparation of shampoo}

The shampoo preparations were made using different percentages of corm extract and other ingredients by weight according to each formula shown in table 1 . Sodium metabisulphite was dissolved in aqua. Then the corm extract was added at $40{ }^{\circ} \mathrm{C}$ (mixture A). HPMC was dispersed slightly in hot water $\left(60-70{ }^{\circ} \mathrm{C}\right)$, the mixture was then stirred and agitated, and allowed to stand until reaching a 
temperature of $20-25^{\circ} \mathrm{C}$ or lower; a homogeneous HPMC solution (mixture B) was thus produced. Sodium lauryl ether sulphate was dissolved in enough water until homogeneous, then cocamidopropyl betaine, propylene glycol, and methylparaben were added and mixed until homogenized (mixture C). Mixtures B and $\mathrm{A}$ were added to $\mathrm{C}$, then mixed with aqua dest until homogenous. Then banana perfume was added and citric acid was used to adjust the $\mathrm{pH}$ to 6 .

Table 1: Shampoo formulas prepared with Musa acuminata corm extract

\begin{tabular}{|c|c|c|c|c|}
\hline \multirow[t]{3}{*}{ Materials } & \multicolumn{4}{|c|}{ Hair tonic shampoo } \\
\hline & \multicolumn{4}{|c|}{ Amount (\%) } \\
\hline & F0 & F1 & F2 & F3 \\
\hline Corm extract & 0.0 & 8.00 & 10.00 & 12.00 \\
\hline Methylparaben & 0.15 & 0.15 & 0.15 & 0.15 \\
\hline Propylparaben & 0.05 & 0.05 & 0.05 & 0.05 \\
\hline Sodium metabisulphite & 0.10 & 0.10 & 0.10 & 0.10 \\
\hline Sodium lauryl ether sulphate & 12.00 & 12.00 & 12.00 & 12.00 \\
\hline HPMC* & 1.75 & 1.75 & 1.75 & 1.75 \\
\hline Cocamidopropyl betaine & 4.00 & 4.00 & 4.00 & 4.00 \\
\hline Propylene glycol & 8.00 & 8.00 & 8.00 & 8.00 \\
\hline Stearic acid & q. $s$. & q. s. & q. $s$. & q. s. \\
\hline Parfum & q. $s$. & q. s. & q. $s$. & q. s. \\
\hline Aquadest ad & 100 & 100 & 100 & 100 \\
\hline
\end{tabular}

*HPMC = Hydroxypropyl methylcellulose

\section{Shampoo evaluation}

The shampoo formulas were evaluated for organoleptic properties, homogeneity, $\mathrm{pH}$, density, surface tension, foam height and stability, and rheology. The organoleptic evaluation included assessments of colour, odour, and form of the shampoo. The $\mathrm{pH}$ was determined with a $10 \%$ aqueous solution of shampoo and measured using a $\mathrm{pH}$ meter at room temperature [9]. A $0.1 \%$ shampoo solution was used for measuring the surface tension using a tensiometer [12].

\section{Evaluation of foaming ability and stability of foam}

Foaming ability was determined by shaking $50 \mathrm{ml}$ of $0.1 \%$ shampoo solution in a covered graduated glass cylinder $(250 \mathrm{ml})$ for $20 \mathrm{~s}$ Foam height was measured to determine its stability. Foam stability was measured twice for each formula after shaking for $20 \mathrm{~s}$ and storage for $20 \mathrm{~min}$ [9].

\section{Rheology evaluation}

Viscosity was determined with a Brookfield RV viscometer (Brookfield Engineering Laboratories, Stoughton, Mass., USA) at rpm of $0.5,1,2,2.5,4$, and 5 with spindle \#6 attached. The viscosity of all shampoo formulas was measured in triplicate at room temperature. The rheology of the formulas was determined by calculating curves for the rate of shear (rpm) versus shearing stress (F/A) [13]

\section{Stability tests}

The shampoo formulas were stored at room temperature and $60^{\circ} \mathrm{C}$ The evaluation was made every week for three weeks using a modification of Colgan et al.'s method. Every preparation was evaluated for organoleptic properties, $\mathrm{pH}$, homogeneity, specific gravity, surface tension, foam height and stability, and rheology [14].

\section{RESULTS AND DISCUSSION}

\section{Characterization of the Musa acuminata corm extract}

The corm extract was liquid in form, with a light odour of banana and a yellowish-white colour (fig. 1 and table 2). The extract had a $\mathrm{pH}$ of 7.22, which affected the formulation of shampoo in the next step in this study.

\section{Phytochemical screening of the corm extract}

The results of the phytochemical screening are given in table 3 . The flavonoid test produced an orange colour in the amyl alcohol layer, indicating that the extract contained flavonoids. The saponin test resulted in the formation of stable foam, indicating the presence of saponins. The test for tannin compounds resulted in an orange colour rather than a brownish-green or blue-black colour; therefore, the extract did not contain tannins. The test for anthraquinones gave a yellow filtrate, indicating that the extract contained anthraquinones [11]. Therefore, these results show that $M$. acuminata corm extract may be able to promote hair growth and can be used in tonic shampoo preparations.

\section{Shampoo evaluation}

The shampoo formulas were thick solutions, yellowish-white in colour, and with the characteristic odour of M. acuminata (fig. 2 and table 4).

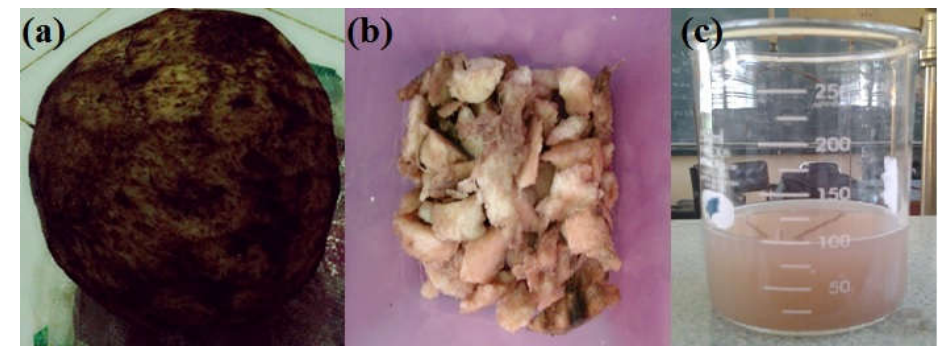

Fig. 1: Musa acuminata Colla (a) corm, (b) sliced corm, and (c) corm extract

Table 2: Organoleptic properties and pH of Musa acuminata corm extract

\begin{tabular}{ll}
\hline Evaluation & Result \\
\hline Form & liquid \\
Odour & light bananas \\
Colour & yellowish-white \\
$\mathrm{pH}$ & 7.22 \\
\hline
\end{tabular}


Table 3: Phytochemical screening of Musa acuminata corm extract

\begin{tabular}{llll}
\hline No & Substance & Result \\
\hline 1 & Flavonoids & Orange layer & + \\
2 & Saponins & Stable foam & + \\
3 & Tannins & Orange colour & - \\
4 & Anthraquinones & Yellow filtrate & + \\
\hline
\end{tabular}

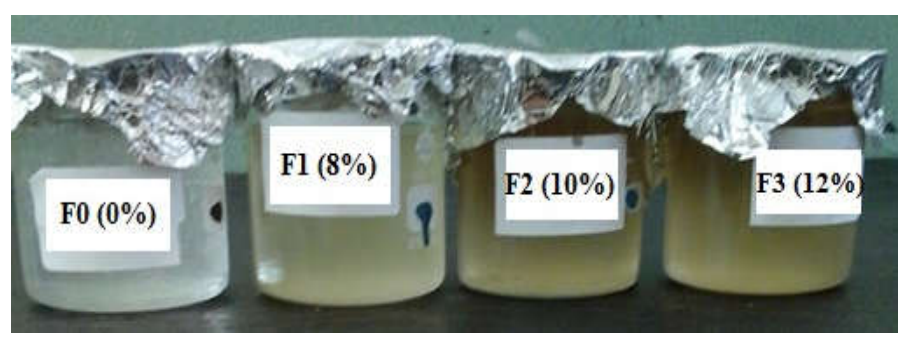

Fig. 2: Shampoo formulas prepared with Musa acuminata corm extract

Table 4: The results of the tests for organoleptic properties of the shampoo formulas prepared with Musa acuminata corm extract. Fo formula did not include the extract, and F1, F2 and F3 consisted of $8 \%, 10 \%$ and $12 \%$ extract, respectively

\begin{tabular}{lllll}
\hline Temperature $\left({ }^{\circ} \mathbf{C}\right)$ & Formula & Form & Colour & Odour \\
\hline \multirow{2}{*}{$20-30$} & F0 & thick solution & white & odourless \\
& F1 & thick solution & yellowish-white & Musa acuminata Colla \\
& F2 & thick solution & yellowish-white & Musa acuminata Colla \\
60 & F3 & thick solution & yellowish-white & Musa acuminata Colla \\
& F0 & thick solution & white & odourless \\
& F1 & thick solution & yellowish-white & Musa acuminata Colla \\
& F2 & thick solution & yellowish-white & Musa acuminata Colla \\
& F3 & thick solution & yellowish-white & Musa acuminata Colla \\
\hline
\end{tabular}

The organoleptic characteristics were caused by the physical mixing of the extract and the other components of the shampoo. Thick shampoo is more trusted by consumers because they believe it works better than thin shampoos [16]. All shampoo formulas in this study are expected to work well.

The results of tests for homogeneity and $\mathrm{pH}$ are given in table 5 . All shampoo formulas were homogeneous, indicating that the active ingredients of the corm extract were evenly distributed. The shampoo formulas were slightly acidic (pH 6.08-6.12). The increase in the concentration of the extract in the shampoo formula can increase its $\mathrm{pH}$ [17]. The $\mathrm{pH}$ of the corm extract was 7.22, which is almost close to neutral, whereas the $\mathrm{pH}$ of the formula without extract (F0) was 6.06; consequently, the formulas with the extract had an intermediate $\mathrm{pH}$. Detergents in most shampoos have an alkaline $\mathrm{pH}$, which can cause swelling of the hair shaft [16]. The $\mathrm{pH}$ of our formulas is in the range of normal skin $\mathrm{pH}$ (4.5-6.5). Therefore, our shampoo formulas are not expected to irritate the skin and are safe to use.

The densities of all the formulas are within the range specified for shampoos by Indonesia National Standard (SNI) of about $1.02 \mathrm{~g} / \mathrm{ml}$ at $20-25^{\circ} \mathrm{C}$. The increase in density from $\mathrm{F} 1$ to $\mathrm{F} 3$ was caused by the difference in the concentration of the corm extract in each formula. The shampoo formulas also produced enough foam; foam heights of the formulas were more than that of $\mathrm{F} 0$, and in all cases, the foam was stable after $300 \mathrm{~s}$ in storage (table 6). A good shampoo produces sufficient foam when shaken with water and, therefore, foam is an important parameter in the evaluation process [15]. In our study, there was sufficient foam on the liquid layer covering more than half of the test tube when examined; therefore, all the shampoo formulas produced foam with a good height and stability.

\section{Rheology evaluation}

The results for the rheology test of shampoo extracts are presented in fig. 3 . The curves show a slower increase of the shearing rate, after an initial rapid increase, because it takes some time for the shampoo formulas to recover viscosity after cessation of stress. This suggests a breakdown of structures that do not recover immediately if stress is removed or raised [15]. Therefore, the shampoo formulas had pseudoplastic thixotropic rheology. These rheological properties will result in each shampoo being able to be poured easily from the bottle into the palm of the hand for application to the hair, and elimination of dripping through the fingers or down the face and neck [18].

Table 5: Homogeneity, pH, density and surface tension of shampoo formulas prepared with Musa acuminata corm extract. F0 formula did not include the extract, and F1, F2 and F3 consisted of $8 \%, 10 \%$ and $12 \%$ extract, respectively

\begin{tabular}{llllll}
\hline Temperature $\left({ }^{\circ} \mathbf{C}\right)$ & Formula & Homogeneity & pH & Density (g/ml) & Surface tension (dyne/cm) \\
\hline \multirow{2}{*}{$20-30$} & F0 & homogeneous & $6.06 \pm 0.04$ & $1.045 \pm 0.02$ & $27.99 \pm 0.04$ \\
& F1 & homogeneous & $6.08 \pm 0.04$ & $1.049 \pm 0.02$ & $28.92 \pm 0.05$ \\
& F2 & homogeneous & $6.09 \pm 0.04$ & $1.051 \pm 0.02$ & $27.99 \pm 0.05$ \\
60 & F3 & homogeneous & $6.12 \pm 0.04$ & $1.053 \pm 0.02$ & $29.85 \pm 0.05$ \\
& F0 & homogeneous & $6.06 \pm 0.04$ & $1.045 \pm 0.02$ & $27.99 \pm 0.04$ \\
& F1 & homogeneous & $6.08 \pm 0.04$ & $1.049 \pm 0.02$ & $28.92 \pm 0.05$ \\
& F2 & homogeneous & $6.09 \pm 0.04$ & $1.051 \pm 0.02$ & $27.99 \pm 0.05$ \\
& F3 & homogeneous & $6.12 \pm 0.04$ & $1.053 \pm 0.02$ & $29.85 \pm 0.05$ \\
\hline
\end{tabular}

Note: The data are given as mean $\pm \operatorname{SD}(n=3)$. 
Table 6: The height and stability of foam produced by shampoo formulas prepared with Musa acuminata corm extract. F0 formula did not include the extract, and F1, F2 and F3 consisted of $8 \%, 10 \%$ and $12 \%$ extract, respectively

\begin{tabular}{|c|c|c|c|c|c|}
\hline \multirow[t]{2}{*}{ Temperature $^{\circ} \mathrm{C}$} & \multirow[t]{2}{*}{ Time of storage after foam formed (s) } & \multicolumn{4}{|c|}{ Height and stability of foam (ml) } \\
\hline & & F0 & F 1 & F 2 & F 3 \\
\hline \multirow[t]{2}{*}{$20-30$} & 20 & $3.55 \pm 0.04$ & $3.58 \pm 0.05$ & $3.62 \pm 0.04$ & $3.67 \pm 0.05$ \\
\hline & 300 & $3.45 \pm 0.04$ & $3.56 \pm 0.05$ & $3.50 \pm 0.05$ & $3.63 \pm 0.04$ \\
\hline \multirow[t]{2}{*}{60} & 20 & $3.55 \pm 0.05$ & $3.58 \pm 0.06$ & $3.62 \pm 0.04$ & $3.67 \pm 0.05$ \\
\hline & 300 & $3.45 \pm 0.08$ & $3.56 \pm 0.08$ & $3.50 \pm 0.05$ & $3.63 \pm 0.08$ \\
\hline
\end{tabular}

Note: Data are presented as mean $\pm \operatorname{SD}(n=3)$.

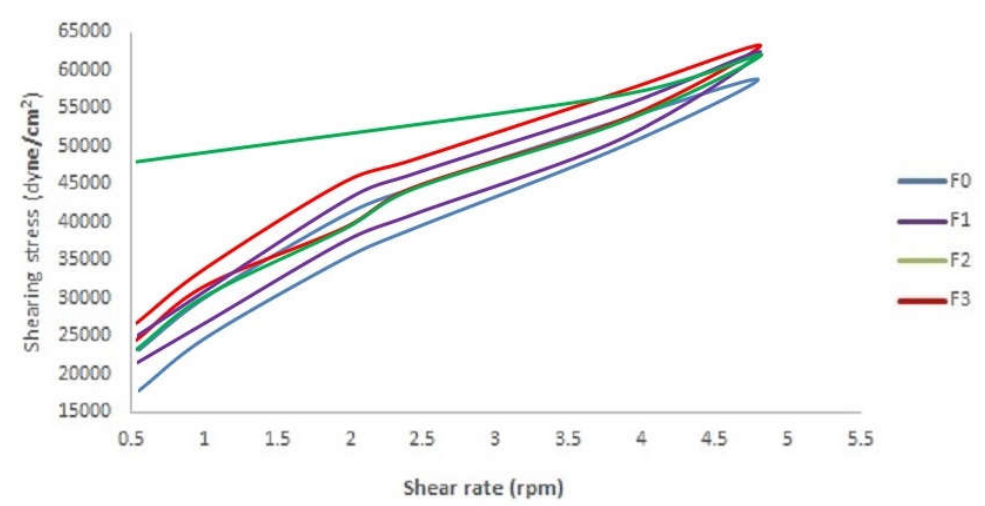

Fig. 3: The result of rheology tests of the shampoo formulas prepared with Musa acuminata corm extract. Fo formula did not include the extract, and F1, F2 and F3 consisted of $8 \%, 10 \%$ and $12 \%$ extract, respectively

\section{Stability test}

The results of the stability test of shampoo formulas are given in table 7 and fig. 4-9. None of the shampoo formulas showed changes in odour, colour, form, homogeneity, $\mathrm{pH}$, density, surface tension, and foam height and stability after storage at room temperature $(25-$ $30{ }^{\circ} \mathrm{C}$ ) and at $60{ }^{\circ} \mathrm{C}$. This suggests that all shampoo formulas are stable in storage at room temperature and $60^{\circ} \mathrm{C}$ for $21 \mathrm{~d}$.

Table 7: The organoleptic properties of the shampoo formulas prepared with Musa acuminata corm extract after storage at room temperature and $60^{\circ} \mathrm{C}$. Fo formula did not include the extract, and F1, F2 and F3 consisted of $8 \%, 10 \%$ and $12 \%$ extract, respectively

\begin{tabular}{|c|c|c|c|c|c|c|c|c|c|c|c|c|c|c|c|c|c|}
\hline \multirow{2}{*}{$\begin{array}{l}\text { Temperature ( } \\
\left.{ }^{\circ} \mathrm{C}\right)\end{array}$} & \multirow{2}{*}{$\begin{array}{l}\text { Time } \\
\text { (day) }\end{array}$} & \multicolumn{4}{|c|}{ Form } & \multicolumn{3}{|c|}{ Colour } & \multicolumn{5}{|c|}{ Odour } & \multicolumn{4}{|c|}{ Homogeneity } \\
\hline & & F0 & F1 & F2 & F3 & F0 & F1 & F2 & F3 & F0 & F1 & F2 & F3 & F0 & F1 & F2 & F3 \\
\hline \multirow[t]{4}{*}{$25-30$} & 0 & TS & TS & TS & TS & $\mathrm{W}$ & YW & YW & YW & B & B & $\mathrm{B}$ & $\mathrm{B}$ & $\mathrm{H}$ & $\mathrm{H}$ & $\mathrm{H}$ & $\mathrm{H}$ \\
\hline & 7 & TS & TS & TS & TS & W & YW & YW & YW & B & B & B & B & $\mathrm{H}$ & $\mathrm{H}$ & $\mathrm{H}$ & $\mathrm{H}$ \\
\hline & 14 & TS & TS & TS & TS & $\mathrm{W}$ & YW & YW & YW & B & B & $\mathrm{B}$ & B & $\mathrm{H}$ & $\mathrm{H}$ & $\mathrm{H}$ & $\mathrm{H}$ \\
\hline & 21 & TS & TS & TS & TS & W & YW & YW & YW & B & B & B & B & $\mathrm{H}$ & $\mathrm{H}$ & $\mathrm{H}$ & $\mathrm{H}$ \\
\hline \multirow[t]{4}{*}{60} & 0 & TS & TS & TS & TS & $\mathrm{W}$ & YW & YW & YW & B & B & B & B & $\mathrm{H}$ & $\mathrm{H}$ & $\mathrm{H}$ & $\mathrm{H}$ \\
\hline & 7 & TS & TS & TS & TS & $\mathrm{W}$ & YW & YW & YW & B & B & $\mathrm{B}$ & B & $\mathrm{H}$ & $\mathrm{H}$ & $\mathrm{H}$ & $\mathrm{H}$ \\
\hline & 14 & TS & TS & TS & TS & $\mathrm{W}$ & YW & YW & YW & B & B & B & B & $\mathrm{H}$ & $\mathrm{H}$ & $\mathrm{H}$ & $\mathrm{H}$ \\
\hline & 21 & TS & TS & TS & TS & W & YW & YW & YW & B & B & B & B & $\mathrm{H}$ & $\mathrm{H}$ & $\mathrm{H}$ & $\mathrm{H}$ \\
\hline
\end{tabular}

Note: $\mathrm{TS}=$ thick solution; $\mathrm{W}=$ white; $\mathrm{YW}=$ yellowish-white; $\mathrm{B}=$ banana odour; $\mathrm{H}=$ homogeneous.

(a)

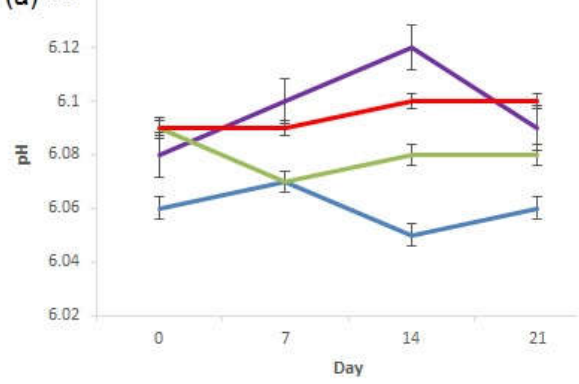

(b) 6.14

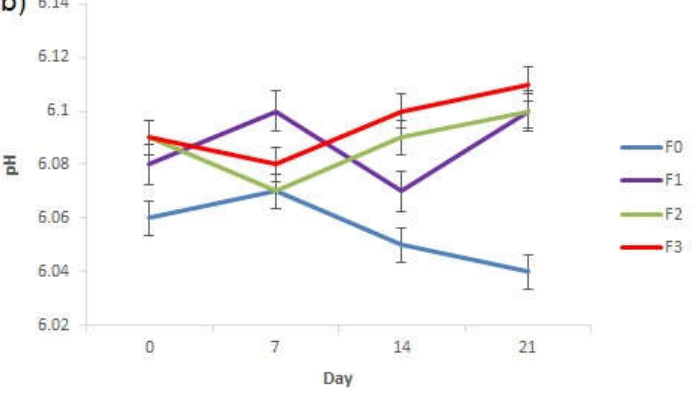

Fig. 4: pH of the shampoo formulas prepared with Musa acuminata corm extract at (a) room temperature and (b) $60{ }^{\circ} \mathrm{C}$. $\mathrm{F0}$ formula did not include the extract, and F1, F2 and F3 consisted of $8 \%, 10 \%$ and $12 \%$ extract, respectively 

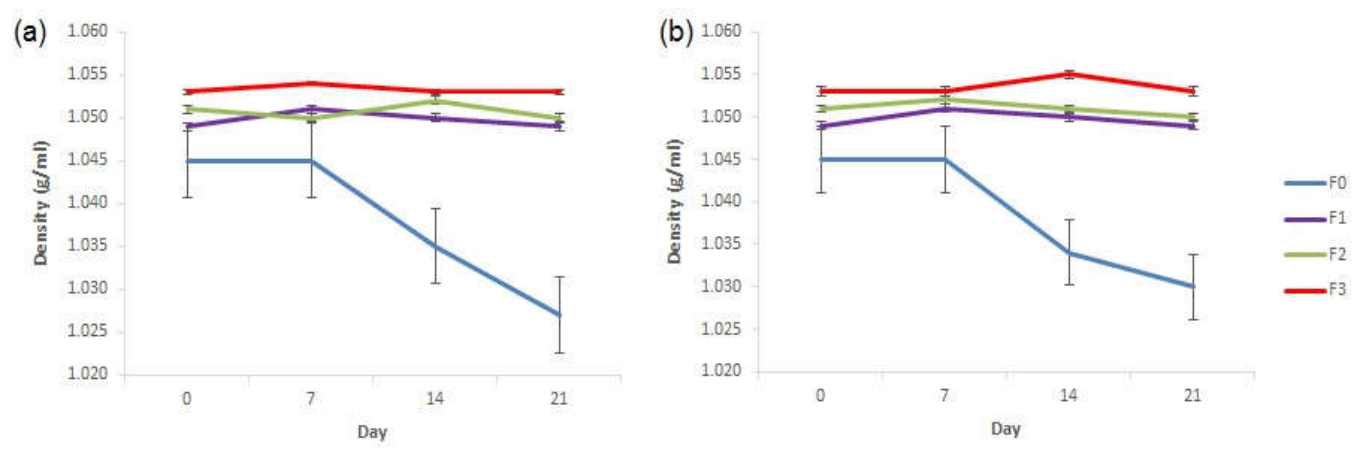

Fig. 5: Density of the shampoo formulas prepared with Musa acuminata corm extract at (a) room temperature, and (b) $60{ }^{\circ} \mathrm{C}$. F0 formula did not include the extract, and F1, F2 and F3 consisted of $8 \%, 10 \%$ and $12 \%$ extract, respectively
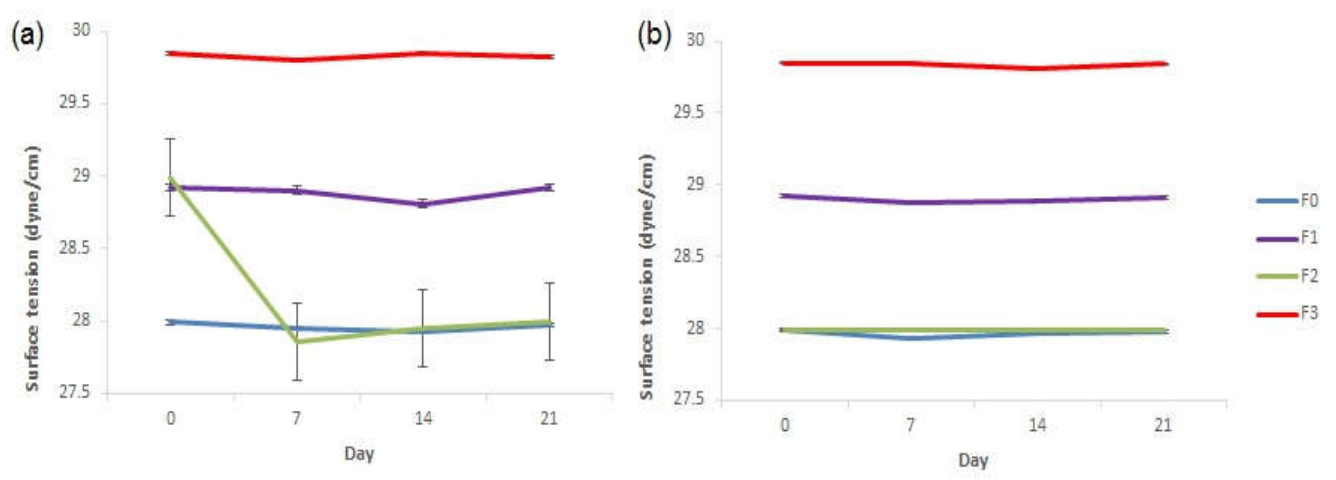

Fig. 6: Surface tension of the shampoo formulas prepared with Musa acuminata corm extract at (a) room temperature, and (b) $60{ }^{\circ} \mathrm{C}$. F0 formula did not include the extract, and F1, F2 and F3 consisted of $8 \%, 10 \%$ and $12 \%$ extract, respectively
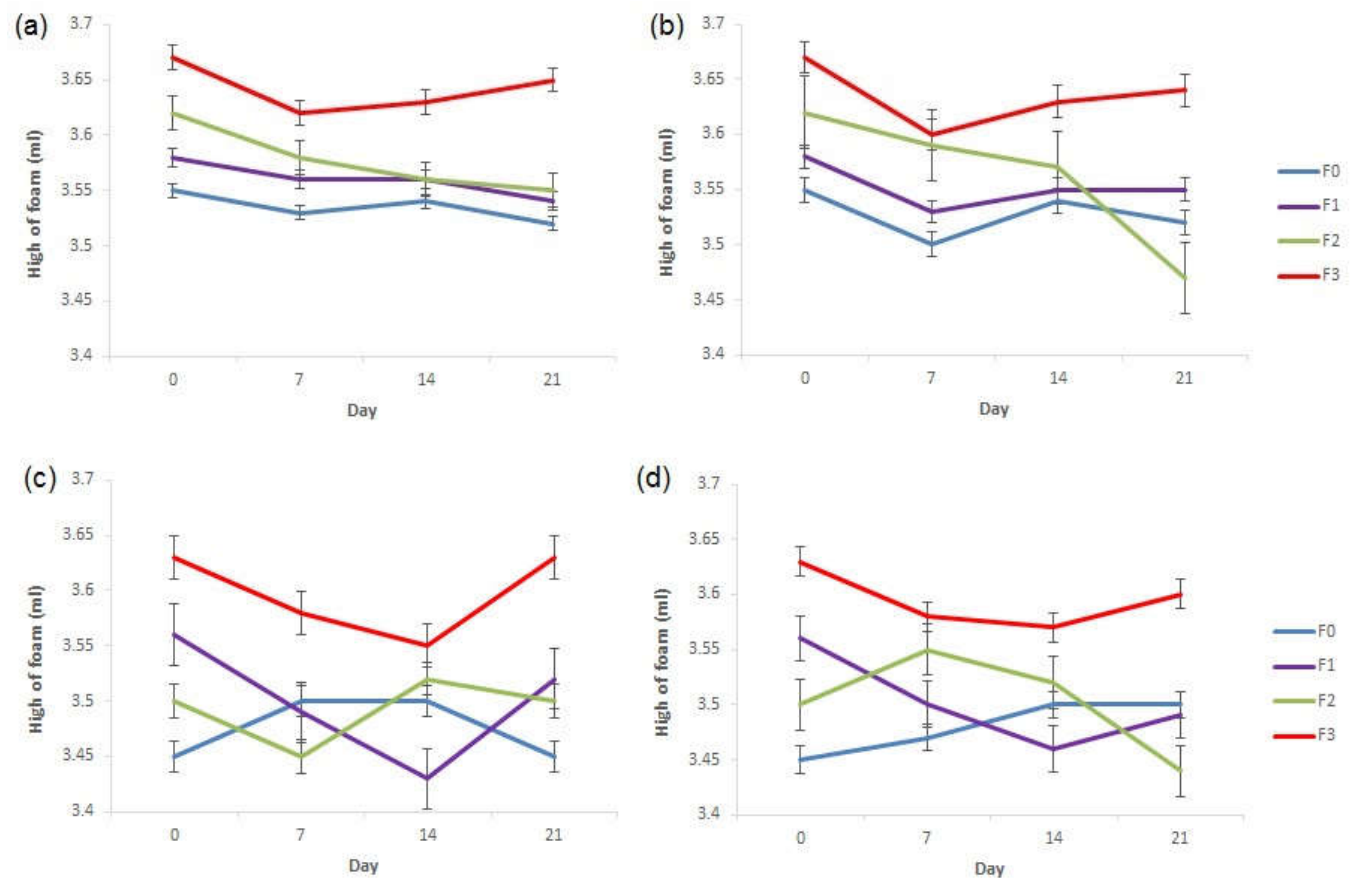

Fig. 7: The stability of foam height of shampoo formulas prepared with Musa acuminata corm extract at (a) $20 \mathrm{~s}$ after shaking at room temperature; (b) $20 \mathrm{~s}$ after shaking at $60^{\circ} \mathrm{C}$; (c) $5 \mathrm{~m}$ aging after shaking at room temperature; and (d) $5 \mathrm{~m}$ aging after shaking at $60{ }^{\circ} \mathrm{C}$. Fo formula did not include the extract, and F1, F2 and F3 consisted of $8 \%, 10 \%$ and $12 \%$ extract, respectively 

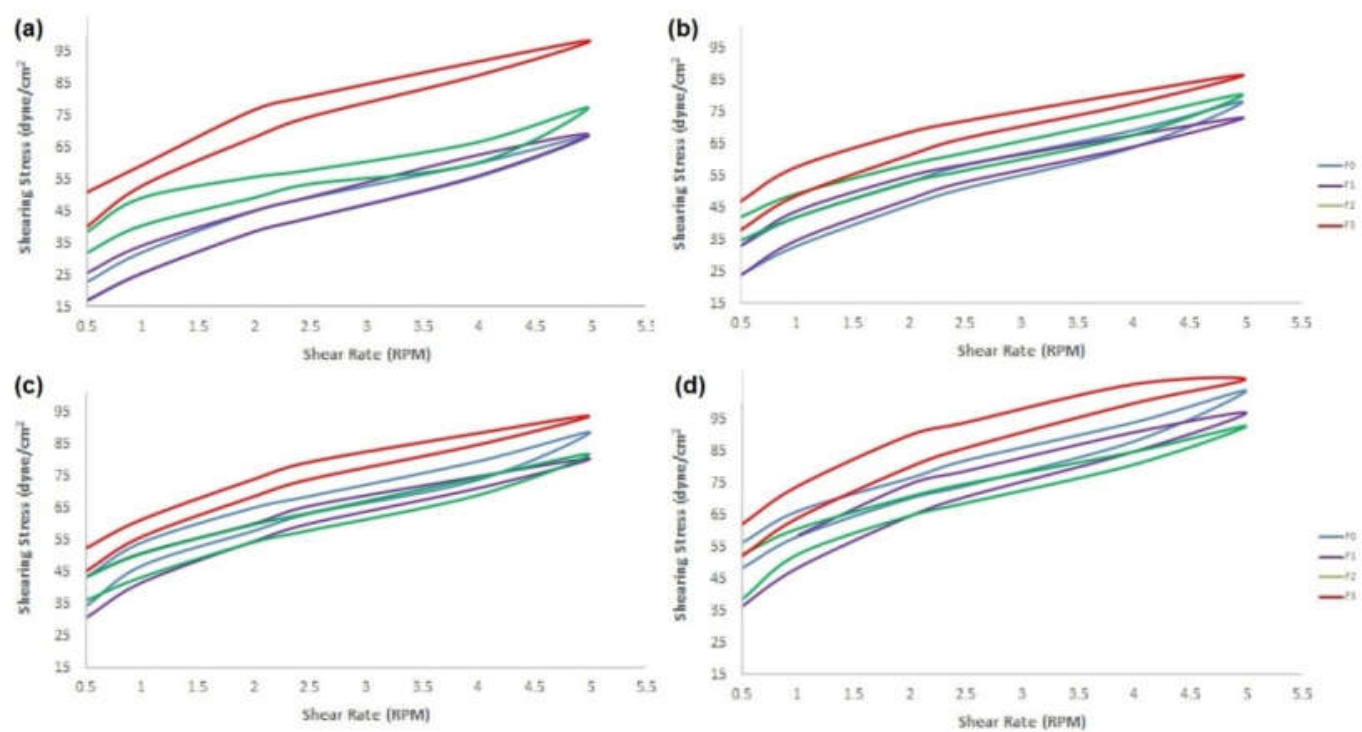

Fig. 8: The rheology of shampoo formulas prepared with Musa acuminata corm extract stored at room temperature: (a) at day 0; (b) at day 7; (c) at day 14; and (d) at day 21 . Fo formula did not include the extract, and F1, F2 and F3 consisted of 8\%, 10\% and $12 \%$ extract, respectively
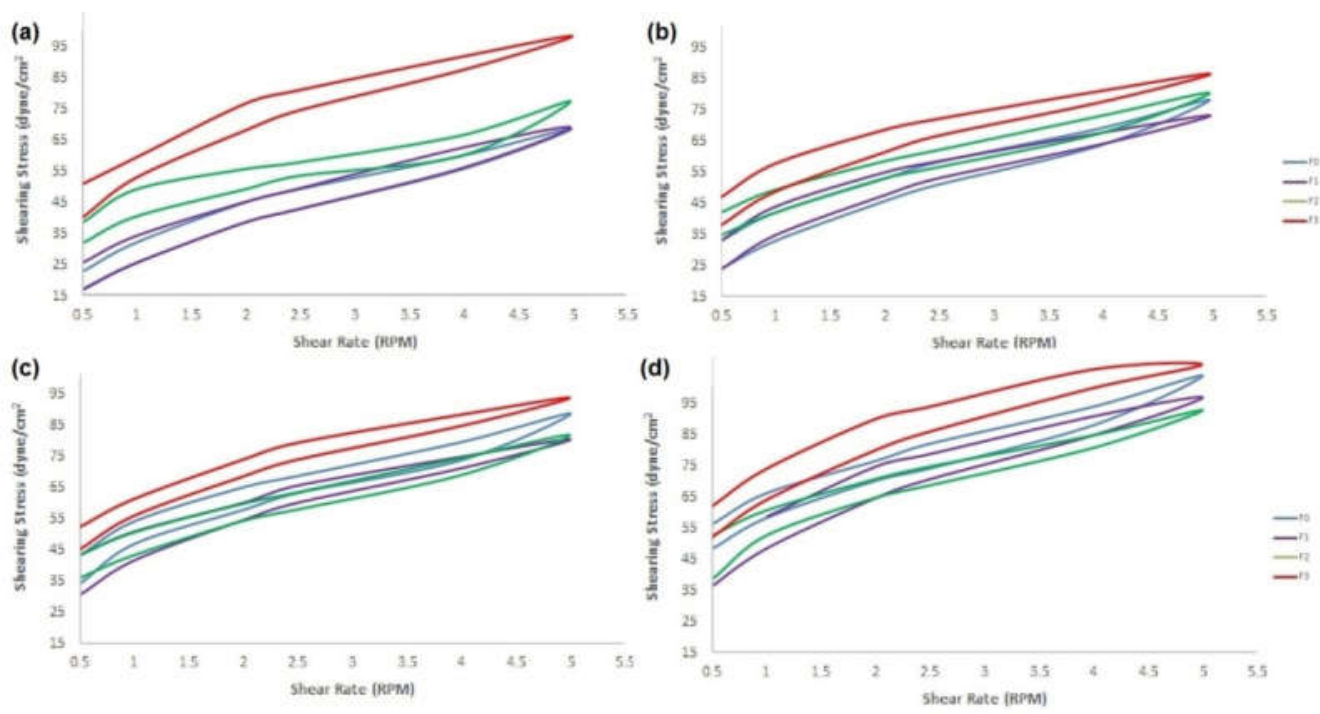

Fig. 9: The rheology of shampoo formulas prepared with Musa acuminata corm extract stored at $60^{\circ} \mathrm{C}$ : (a) at day 0; (b) at day 7; (c) at day 14; and (d) at day 21 . Fo formula did not include the extract, and F1, F2 and F3 consisted of $8 \%, 10 \%$ and $12 \%$ extract, respectively

The rheology of shampoo is highly temperature-dependent (fig. 8 and 9). The viscosity of shampoo decreased by approximately $10 \%$. The efficiency and quality of the production process will affect the rheological properties of fluid systems $[19,20]$. The curves in fig. 8 and 9 show that all formulas were still in pseudoplastic thixotropic rheology after storage for three weeks at room temperature (20-30 ${ }^{\circ} \mathrm{C}$ ) and $60{ }^{\circ} \mathrm{C}$. Therefore, the rheological properties of all formulas were stable in storage for $21 \mathrm{~d}$ at the two temperatures tested.

The results of all the evaluations show that the quality of all three tonic shampoo formulas is good and that they are safe and easy to apply. They are also more stable than the sap of the banana corm used traditionally. The next phase of the research is to study the effectiveness of the shampoo to promote bushy and black hair growth. The results of our study demonstrate that a waste byproduct, i.e. the corm, of Ambon banana cultivation can be successfully used for shampoo preparation, providing an avenue for extending the use of the plant and generating further profitability.

\section{CONCLUSION}

The M. acuminata corm can be used for preparing shampoo formulations, demonstrating a profitable use of a waste by-product of cultivation. All shampoo formulas made with different proportions of corm extract are of good quality and stable at room temperature. All formulas have a thick form, and are yellowish-white in colour, with the odour of M. acuminata. The shampoo formulas are homogeneous and have a $\mathrm{pH}$ of $6.08-6.12$, density of 1.049$1.053 \mathrm{~g} / \mathrm{ml}$, and surface tension of $28.92-29.85 \mathrm{dyne} / \mathrm{cm}$, and the stability of foam height was between $3.56-3.63 \mathrm{ml}$. The formulas have a viscosity of $16,000-120,000$ cps and pseudoplastic thixotropic rheology. 


\section{FUNDING}

$\mathrm{Nil}$

\section{AUTHORS CONTRIBUTIONS}

Teti Indrawati (TI), Lastiar Simanjuntak (LS), and Diah Kartika Pratami (DKP) provided critical feedback and helped shape the research, analysis and manuscript. TI and LS conceived and planned the experiments. LS carried out the experiments, planned and carried out the simulations. TI contributed to sample preparation. TI and DKP contributed to the interpretation of the results. DKP took the lead in writing the manuscript.

\section{CONFLICT OF INTERESTS}

There is no conflict of interest.

\section{REFERENCES}

1. Indrawati $\mathrm{T}$, Sofia $\mathrm{N}$. Creambath formulation with concentration variation water extracts of Ambon banana weevil (Musa acuminata Colla). J Ilmu Kefarmasian Indones 2018;16:56-60

2. Erawan TS, Hidayat RA, Iskandar J. Ethnobotanical study on banana in Karangwangi Village, Cianjur District, West Java. Biodjati 2019;4:112-25.

3. Hapsari L, Lestari DA. Fruit characteristic and nutrient values of four Indonesian banana cultivars (Musa spp.) at different genomic groups. J Agric Sci 2016;38:303-11.

4. Kumar KPS, Bhowmik D, Duraivel S, Umadevi M. Traditional and medicinal uses of banana. J Pharmacogn Phytochem 2012;1:51-63.

5. Kusuma SAF, Soraya RM, Indah F, Resmi M. Study on the antibacterial activity of fruit extracts of Klutuk Banana (Musa balbisiana Colla) against Shigella dysenteriae ATCC 13313 Asian J Pharm Clin Res 2017;10:220-3.

6. Pereira A, Maraschin M. Banana (Musa spp) from peel to pulp ethnopharmacology, source of bioactive compounds and its relevance for human health. J Ethnopharmacol 2015:160:149-63.

7. Shahi Z, Mehrizi MK, Hadizadeh M. A review of the natural resources used to hair color and hair care products. J Pharm Sci Res 2017;9:1026.
8. Gupta A, Malviya R, Singh TP, Sharma PK. Indian medicinal plants used in hair care cosmetics: a short review. Pharmacogn J 2010;2:361-4.

9. Al Badi K, Khan SA. Formulation, evaluation and comparison of the herbal shampoo with commercial shampoos. Beni-Suef Univ J Basic Appl Sci 2014;3:301-5.

10. Amin J, Simamora ELP, Anwar E, Djajadisastra J. Green tea (Camellia sinensis, L.) ethanolic extract as hair tonic in nutraceutical: physical stability, hair growth activity on rats, and safety test. Int J Pharm Pharm Sci 2014;6:94-9.

11. Munir A, Mehmood A, Azam S. Structural and function prediction of Musa acuminata subsp. malaccensis protein. Int J Bioautomation 2016;20:19-30.

12. Lee $\mathrm{S}$, Lee $\mathrm{J}, \mathrm{Yu} \mathrm{H}$, Lim J. Synthesis of environment-friendly biosurfactants and characterization of interfacial properties for cosmetic and household products formulations. Colloids Surf A 2018;536:224-33.

13. Ali HS, Shehab NA, Mohamed E, Ahaj B. Formulation and evaluation of herbal cream from Ziziphus spina leaves extract. Int Res J Pharm 2013;4:44-8.

14. Colgan ST, Mazzeo T, Orr R. Regulatory expectations and industry practice on stability testing. In: Accelerated Predictive Stability (APS). Elsevier Inc; 2018. p. 15-32.

15. Dash GK, Husna N, Binti N, Pharmacy F, Sciences H, Perak M, et al. Formulation and evaluation of herbal shampoo. Indo American J Pharm Sci 2017;4:2860-5.

16. Draelos ZD. Shampoos, conditioners, and camouflage techniques. Dermatol Clin 2013;31:173-8.

17. McElwee KJ, Sinclair R. Hair physiology and its disorders. Drug Discovery Today: Dis Mech 2008;5:163-71.

18. Gholamreza Dehghan Noudeh. Formulation of herbal conditioner shampoo by using an extract of fenugreek seeds and evaluation of its physicochemical parameters. Afr J Pharm Pharmacol 2011;5:2420-7.

19. Ren Z, Kowalski A, Rodgers TL. Measuring inline velocity profile of shampoo by electrical resistance tomography (ERT). Flow Measurement Instrumentation 2017;58:31-7.

20. Salih ZT, Algawhari_FA, Rajab NA. Preparation, release, rheology and stability of piroxicam emulgel. Int J Appl Pharm 2018;10:26-9. 